Cómo citar este artículo en Chicago: Moreno Trujillo, María Paulina. "La simbólica del mal en Ensayo sobre la ceguera, de José Saramago: la mancha, el pecado y la culpa”. Escritos 29, no. 63 (2021): 237-246. doi: http://doi.org/10.18566/escr.v29n63.a03

Fecha de recepción: 26.02 .2021

Fecha de aceptación: 06.05.2021

\title{
La simbólica del mal en Ensayo sobre la ceguera, de José Saramago: la mancha, el pecado y la culpa
}

\author{
The Symbolic of Evil in Blindness, by José Saramago: Stain, Sin and Guilt
}

\author{
María Paulina Moreno Trujillo ${ }^{1}$
}

\begin{abstract}
RESUMEN
Este artículo realizó un análisis desde la categoría hermenéutica del símbolo según Paul Ricoeur de la novela de José Saramago Ensayo sobre la ceguera, en que, después de definir la categoría de análisis, su importancia y relevancia y el impacto que su comprensión puede tener para comprender situaciones actuales y pertinentes de nuestra sociedad, se procede a desarrollar la categoría con los símbolos escogidos en la novela del pecado, la mancha y la culpa. Haciendo uso no solo de los textos referentes a la hermenéutica de Ricoeur, sino también de La simbólica del mal, se propone un recorrido conceptual para dilucidar cómo se configuran los sentidos y significados de los símbolos del mal en nuestra cultura y mediante esta comprensión abordar la situación del aparato simbólico de la novela de Saramago. Llevar a cabo un análisis de estas categorías hermenéuticas en una novela como Ensayo sobre la ceguera se convierte en la oportunidad de evidenciar un significado y un sentido diferentes de una novela que ha mostrado claramente su relevancia en épocas anteriores y que hoy, en una pandemia, nos invita a repensar ese mundo y a enfrentarnos al hecho de entender nuestra propia ceguera y la ceguera del mundo en medio de una velocidad vertiginosa que nos exige asumir nuestra realidad de otra forma. En palabras de Ricoeur, el símbolo da qué pensar y es momento de que pensemos a través de nuestros propios símbolos la realidad que se nos plantea en la novela de Saramago y la extrapolemos a las realidades que se configuran cada día en nuestro mundo occidental.
\end{abstract}

Palabras clave: Saramago; Hermenéutica; Símbolo; Ricoeur; Culpa; Ceguera; Mal; Confesión; Mancha; Pecado.

\section{ABSTRACT}

This article carried out an analysis from the hermeneutical category of the symbol in the novel Blindness by José Saramago, following Paul Ricoeur, in which the symbols of sin, stain and guilt were chosen to be developed after

1 Magíster en Estudios Humanísticos del Tecnológico de Monterrey, México. Licenciada en Filosofía y Letras de la Universidad Pontificia Bolivariana, Colombia. Asesora del área de Ciencias Sociales en el Colegio Montessori de Medellín. Correo electrónico: polly.moreno9@gmail.com 
defining the relevance and the impact of the category of analysis on current situations in our society. Making use not only of the texts referring to Ricoeur's hermeneutics, but also of The Symbolic of Evil, a conceptual journey is proposed to elucidate how the senses and meanings of the symbols of evil are configured in our culture and, through this understanding, address the situation of the symbolic apparatus of Saramago's novel. Carrying out an analysis of these hermeneutical categories in a novel such as Blindness becomes the opportunity to show a different meaning and sense of a novel that has clearly shown its relevance in previous times and that today, in the middle of a pandemic, invites us to rethink that world and to face the fact of understanding our own blindness and the blindness of the world in the midst of a dizzying speed that requires us to assume our reality in another way. In the words of Ricoeur, the symbol gives food for thought and it is time for us to think through our own symbols about the reality that is presented to us in Saramago's novel and to extrapolate it to the realities that are configured every day in our Western world.

Keywords: Saramago; Hermeneutics; Symbol; Ricoeur; Fault; Blindness; Confession; Stain; Sin; Guilt.

\section{Introducción}

E nsayo sobre la ceguera (1995), novela del premio nobel de literatura portugués José Saramago, en la que se describe una sociedad distópica debido a la aparición de una ceguera contagiosa y colectiva, está colmada de simbolismos, metáforas y analogías que invitan a la interpretación y proponen descubrir en ese segundo plano que apenas se vislumbra una significación ulterior a la de la simple narración de los eventos relatados, y así nos permite acercarnos a la comprensión de nosotros mismos y de la sociedad.

Mediante el análisis de la categoría hermenéutica del símbolo y el desarrollo conceptual de la simbólica del mal, se descubre cómo por medio de los símbolos propios de la confesión del mal se puede lograr una comprensión profunda de la sociedad plasmada por Saramago. Se realiza así un acercamiento a lo humano basado en la premisa que plantea Ricoeur: "El símbolo da qué pensar" y, en este caso, la posibilidad de pensar y repensar nuestra sociedad y nuestra esencia humana mediante una simbólica que nos acompaña desde la adquisición misma de nuestro lenguaje.

Como se mencionó, la categoría hermenéutica de análisis es el símbolo, por tanto, el primer paso es su definición, apoyada en la hermenéutica simbólica de Ricoeur y la evidente relevancia de dicha categoría para el desarrollo de la sociedad y del individuo. Posteriormente, es necesario hablar de lo que significa la simbólica del mal, su confesión y su relevancia en el ámbito interpretativo. Para ello, se retoma la novela de Saramago, puesto que en ella es posible rastrear una constante que remite directamente a aquellos símbolos que hacen parte de lo que Ricoeur denomina simbólica del mal y mediante su interpretación es posible reconocer cómo nuestra sociedad está fundada en la concepción de un pecado original que nos incluye a todos como hombres y que, además, cimienta sus bases en la situación del hombre ante Dios.

Los símbolos a los que se les aplica el análisis hermenéutico en el caso de Ensayo sobre la ceguera son el pecado, la mancha y la culpa. Su selección se debe a la presencia relevante que tienen en la novela, pero también al peso simbólico, puesto que son los pilares del andamiaje de la simbólica del mal y dan cuenta de la condición humana mediante la interpretación de su propio lenguaje y la simbología relacionada con cada uno. Este análisis y la comprensión de los significados profundos de los símbolos mencionados nos permiten elaborar una interpretación de la sociedad plasmada por Saramago que nos guía a evidenciar nuestra propia situación en la sociedad real. 
Así pues, el objetivo general es comprender mediante la simbólica del mal nuestra condición humana dentro de la sociedad planteada por Saramago en Ensayo sobre la ceguera, y para lograrlo se han de conseguir varios objetivos específicos que permitan una conclusión acertada. En primer lugar, desarrollar una interpretación de cada uno de los símbolos considerados en la simbólica del mal y que se hacen presentes en la novela de Saramago; y, en segundo lugar, profundizar en el concepto hermenéutico del símbolo desde la posición de Ricoeur y aplicarlo de tal manera que nos permita acercarnos a la comprensión de las dinámicas humanas mediante la interpretación del lenguaje simbólico de la novela.

\section{El símbolo y la hermenéutica simbólica}

\section{La hermenéutica simbólica}

La hermenéutica simbólica es la disciplina que tiene sus bases como hermenéutica en el planteamiento del problema exegético, es decir, nace también para comprender un texto a partir de su intención y sobre la base de lo que este quiere decir. ${ }^{2}$ Tiene como propósito acortar la distancia y acercar al lector a un texto que le es ajeno para posibilitar su comprensión. La propuesta de Ricoeur radica en injertar la hermenéutica en la fenomenología y articular ambas disciplinas. Es evidente que la teoría ontológica heideggeriana ya había adelantado camino en esta proposición, reconociendo "el comprender no ya como un modo de conocimiento, sino como un modo de ser", ${ }^{3}$ y convirtiendo el problema hermenéutico en una región de la analítica del Dasein en la que el ser como unidad fundamental de las relaciones establecidas en el mundo se convierte en hombre y se expresa a través de un lenguaje que solo puede ser simbólico y que, por tanto, convierte al sentido de la existencia en un sentido también simbólico.

Esta analítica del ser, cuyo elemento principal es el lenguaje, será sustituida en la hermenéutica simbólica por la importancia del símbolo, punto de partida fundamental para la interpretación. La semántica se convierte en la herramienta esencial para aproximarse a la interpretación, puesto que toda comprensión se expresa mediante el lenguaje que genera texturas semánticas propicias a la interpretación. Esta disciplina se organiza en torno a la existencia de significaciones con sentidos múltiples o multívocas, que Ricoeur optará por llamar simbólicas. La interpretación y comprensión de tales sentidos transmitidos por las expresiones simbólicas o multívocas son también un momento de comprensión de sí mismo. "La hermenéutica debería descubrir un modo de existir que fuese, de cabo a cabo, ser-interpretado".

Además, Ricoeur le otorga a la hermenéutica la posibilidad de servir como medio para la comprensión de sí mismo, facultad que es altamente relevante para el desarrollo de esta investigación, puesto que se pretende poder comprender al ser humano en medio de su sociedad mediante la interpretación de los símbolos presentes en su lenguaje. Así pues, los símbolos que aparecen en la novela serán pasados por una estructura de análisis hermenéutico que nos permita descubrir ese sentido velado que proviene de nosotros mismos como lectores. "Al proponer una relación del lenguaje simbólico con la comprensión

2 Paul Ricoeur, El conflicto de las interpretaciones (Buenos Aires: Fondo de Cultura Económica, 2008$), 9$.

3 Ricoeur, El conflicto de las interpretaciones, 11.

4 Ricoeur, El conflicto de las interpretaciones, 16. 
de sí, aspiro a satisfacer el deseo más profundo de la hermenéutica. [...] Hacer propio lo que era ajeno, es decir, hacerlo suyo,", posibilitar la interpretación y la comprensión del símbolo.

\section{El símbolo}

El campo hermenéutico para Ricoeur está delimitado por el concepto de símbolo que podemos considerar como una arquitectura del doble sentido que se encarga de mostrar ocultando, de decir más de lo que dice, de darle a la palabra una segunda instancia. Para este pensador, el concepto de símbolo tiene un sentido más restringido que el que le dieron autores como Cassirer que denomina símbolo a todas las comprensiones de la realidad que se dan mediante un signo, desde el mito hasta la ciencia. Pero también le otorga al símbolo un sentido mucho más amplio que el que se le da en la tradición neoplatónica, en que es reducido a la analogía. "Llamo símbolo a toda estructura de significación donde un sentido directo, primario y literal designa por añadidura otro sentido indirecto, secundario y figurado, que solo puede ser aprehendido a través del primero". ${ }^{6}$

En busca de la definición de una hermenéutica simbólica, es necesario acudir a una dilucidación fundamental de las diferencias entre signo y símbolo. En el signo, hay un vehículo que porta la función significante, es decir, que hace que valga por otra cosa. ${ }^{7}$ La unidad de significación en el signo está compuesta por dos pares de factores: el signo sensible y la significación, y el signo y el objeto designado. En el caso del símbolo, no nos referimos a esta dualidad, sino más bien a una superposición de sentidos en la que la existencia de unos signos con sentido primario nos remite a un segundo sentido mediante la interpretación. Sostiene Ricoeur que "hay interpretación allí donde hay sentido múltiple, y es en la interpretación donde la pluralidad de sentidos se pone de manifiesto". ${ }^{8}$ Volviendo al símbolo, es necesario afirmar que el sentido primario, mundano, literal y, en general, físico, remite a un sentido figurado, espiritual, existencial y ontológico, por lo que apela directamente a una interpretación. "El símbolo da qué pensar" y al hacerlo genera simbólicas que requieren una interpretación, a la cual solo podemos considerar hermenéutica en el momento en que representa una comprensión de sí mismo y del ser.

El símbolo aparece "cuando el lenguaje produce signos de grado compuesto donde el sentido, no conforme con designar una cosa, designa otro sentido que no podría alcanzarse sino en y a través de su enfoque o

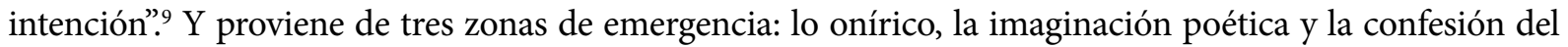
mal. La primera de estas es el espacio del psicoanálisis. En el sueño, "hay un sentido manifiesto que jamás ha dejado de remitir al sentido oculto, cosa que hace de todo durmiente un poeta". El sueño, creador de símbolos, nos es desconocido como tal, solo accedemos a él mediante el lenguaje y es este el que puede ser sometido a interpretación. La segunda zona de emergencia es la imaginación poética que se refiere a la "facultad de deformar las imágenes suministradas por la percepción y, sobre todo, la facultad de librarnos de las imágenes primeras, de cambiar las imágenes"10 para crear símbolos. La tercera zona de emergencia, y

5 Ricoeur, El conflicto de las interpretaciones, 21.

6 Ricoeur, El conflicto de las interpretaciones, 17.

7 Paul Ricoeur, "Para una crítica del símbolo", en Freud: Una interpretación de la cultura (México: Siglo XXI, 1971), $12-21$.

8 Ricoeur, El conflicto de las interpretaciones, 17.

9 Ricoeur, "Para una crítica del símbolo", 12-21.

10 Víctor Florián, introducción a La llama de una vela, de Gaston Bachelard” (Bogotá: Universidad Nacional, 2007$), 6$. 
en esta investigación la más relevante, es la confesión del mal. No hay en el hombre un lenguaje directo que dé cuenta del mal mismo. En dicha confesión, aparecen símbolos extraídos de lo cotidiano que se invisten de un sentido figurado para designar la experiencia de lo sagrado.

El símbolo es la unidad de sentido compuesta por nuestro lenguaje que da cuenta de nuestra realidad y de nosotros mismos; por tanto, Ricoeur nos propone pensar no detrás de los símbolos, sino a partir de ellos, puesto que "constituyen el fondo revelador de la palabra que habita entre los hombres, en suma, el símbolo da qué pensar"."

\section{¿Qué es y de dónde viene la simbólica del mal?}

La simbólica del mal es un compendio de símbolos que proceden de la confesión del mal, dichos símbolos son signos tomados de nuestro lenguaje cotidiano como la mancha, el camino torcido o el peso sobre los hombros, que son imbuidos con una significación ulterior, un segundo sentido que nos permite confesar el mal por medio del lenguaje. Ricoeur plantea que el mal es un reto a la filosofía y a la teología, como lo dice abiertamente en El mal: Un desafío a la filosofía y a la teología, puesto que cualquier filosofía que pretenda totalizar un sistema respondiendo de manera racional a cada una de las preguntas que plantea el hombre encuentra un inconveniente mayor al enfrentarse a la pregunta por el mal y el sufrimiento. El mal se presenta ante nosotros por medio de una confesión relatada, que hace uso de signos, símbolos y mitos para dar cuenta de aquello que experimenta, pero que no puede comprender. Esta vivencia o experiencia es una vivencia de ceguera, de escándalo y de equivocidad. ${ }^{12}$ La conciencia del mal, del pecado, se expresa mediante la palabra y se convierte en símbolo. Ese mal tiene varias capas: el mal cometido y el mal sufrido, que nos llevan a conocer profundamente la condición humana mediada por el lenguaje. "El problema de Dios y el problema del Mal no se agotan con nuestros razonamientos conformes a la no-contradicción y a totalizaciones sistemáticas." ${ }^{13}$

La confesión se da mediante el relato de imágenes cargadas de simbolismo que tienen como fin último exteriorizar una emoción que no puede ser comprendida sino mediante la intervención del lenguaje y del símbolo. Así, el hombre busca llevar a la luz de la comprensión la conciencia de la falta mediante la confesión. El pilar fundamental de la confesión es la situación del pecado, que nos remite a un sentimiento de indignidad y miseria, pero que fundamentalmente agrupa a todos los hombres y su situación ante Dios. Es, pues, el pecado lo que ensombrece la situación del hombre, y su origen es tan profundo que la mayor parte de las veces se escapa a nuestra conciencia; nos separa de Dios estando profundamente ligado a nuestra esencia humana. El cristianismo le ha denominado pecado original, que, en palabras de Ricoeur, "significa una primera cosa: que el mal no es algo que sea, no tiene ser ni naturaleza, porque proviene de nosotros". El pecado original cumple también con la función totalizante del mal, puesto que une a todo el género humano bajo el discurso dogmático del pecado que todos compartimos por el simple hecho de experimentar el mal como humanos: "La experiencia, a la vez individual y comunitaria,

11 Ricoeur, El conflicto de las interpretaciones, 272.

12 Marie-France Begué, “La simbólica del mal de Paul Ricoeur comentada”, Teoliteraria: Revista de Literaturas e Teologias 2, no. 3 (2012): 17-38, https://doi.org/10.19143/2236-9937.2016v2n3p17-38.

13 Begué, "La simbólica del mal de Paul Ricoeur comentada”, 19. 
de la impotencia del hombre frente a la potencia de un mal ya presente antes de cualquier iniciativa mala asignable a alguna intención deliberada". ${ }^{14}$

Existe un símbolo que está ligado al pecado desde sus orígenes: el símbolo de la mancha, de la impureza, que nos remite a la falta, a una conciencia del mal que nos lleva a reclamar de nuevo al lenguaje para que nos interprete. Tal interpretación se da, entonces, por medio de interrogaciones que interpelan la presencia del mal: ¿Por qué a mí? ¿Por qué? ¿Es justo? A lo que el dogma responde que "todo sufrimiento es merecido pues constituye el castigo por un pecado individual o colectivo, conocido o desconocido". ${ }^{5}$ Como hombres, al estar enfrentados con el cuestionamiento del mal o el sufrimiento, entramos en contacto con un oscurecimiento del sentido que no nos permite comprender los sucesos. El hecho de cuestionar, de preguntar, implica la presencia de otro; al ponernos en diferencia con ese otro, logramos un estado de alienación de nosotros mismos, que nos permite concluir que la experiencia del pecado, de la miseria y de la falta, es una experiencia que genera ruptura en el ser humano. Dicha ruptura es la que ocasiona la necesidad de un lenguaje particular para ser comunicada, expresada y comprendida. Lenguaje que está cargado de imágenes simbólicas: el relato de la falta, del origen y del pecado hace uso de signos particulares que van más allá de su función en el simple relato. "Hay una verdadera poética confesional de la falta que produce sus símbolos y metáforas con una determinada significación, pero que a través de ellos se está queriendo decir otra cosa, se apunta una segunda significación”. ${ }^{16}$

\section{Símbolos de la confesión del mal en Ensayo sobre la ceguera}

\section{La mancha y el pecado}

El símbolo de la mancha es el realismo del pecado y su concordancia con la ceguera presentada por Saramago. El pecado es mi situación ante Dios y mi conciencia no es la medida de este, por lo que se hace necesaria la presencia de otro; un profeta que pueda denunciarlo. La palabra profeta proviene de la voz griega que designa al intérprete, a quien habla por otro; en la novela, encontramos la existencia de un profeta que ve, que interpreta para los demás y que a su vez es quien denuncia el mal en ellos y en el mundo que los rodea. La mujer del ciego asume el papel del profeta, interpreta el mundo donde viven y define con cuidado el impacto del pecado (la ceguera) en la sociedad. "Quizá tengas razón, pero la experiencia de esta ceguera solo nos ha traído muerte y miseria". ${ }^{17}$

El segundo rasgo es que el pecado incluye a los hombres como cuerpo; la condición del pecador es irreductible a una noción de culpabilidad individual. "Esta solidaridad transbiológica y transhistórica del pecado constituye la unidad metafísica del género humano", ${ }^{18}$ dice uno de los personajes de la novela de Saramago: "Hay en nosotros una cosa que no tiene nombre, esa cosa es lo que somos"; ${ }^{19}$ ese "nosotros"

14 Ricoeur, El conflicto de las interpretaciones, 272.

15 Ricoeur, El conflicto de las interpretaciones, 326.

16 Begué, "La simbólica del mal comentada", 24.

17 José Saramago, Ensayo sobre la ceguera (Lisboa: Caminho, 1995), 578.

18 Ricoeur, El conflicto de las interpretaciones, 257.

19 Saramago, Ensayo sobre la ceguera, 3. 
se refiere a "nosotros, pobres ciegos", que es también el "nosotros, pobres pecadores", que enuncia la confesión de los pecados.

El tercer rasgo del pecado que observamos claramente es que este es algo que mantiene atado y cautivo al hombre: es el pecado como "miseria". La experiencia del cautiverio se hace evidente en el espacio físico de cuarentena al que son condenados los ciegos, sin embargo, el cautiverio persiste después de salir al mundo exterior, puesto que es el pecado, la ceguera, lo que los mantiene cautivos. La condición de mancha y miseria, referentes también de este mismo rasgo del pecado, permanecen en ellos y con ellos, vayan donde vayan.

Ya sea por relación analógica o por similitud, la mancha me llevará a hablar desde el punto de vista de miseria, impureza, inmundicia, porquería, etc. Sostiene Saramago que "la experiencia de esta ceguera solo nos ha traído muerte y miseria”, ${ }^{20}$ y ha abierto la puerta para la interpretación del símbolo en la sociedad; es la ceguera humana, la culpa y el pecado (posiblemente el del conocimiento) lo que ha causado al hombre los más grandes males y sufrimientos a lo largo de la historia. Es esa ceguera humana frente a la situación del otro la que finalmente nos sume en un mundo de miseria donde la sociedad se rige por principios monetarios y no humanizantes.

La mancha es una señal o marca, en general de suciedad, pero también es la deshonra, el deshonor, eso que disminuye la dignidad, la estima y la respetabilidad de una persona. Parece ya adquirir su carácter simbólico al atribuirle un significado figurado como el del deshonor; sin embargo, símbolos como el de la mancha parecen simples al compararlos con aquellos que ya llegan al nivel del mito, como el de la caída. La mancha está aún en el primer nivel de significación del símbolo; está indiscutiblemente ligada al peligro de la suciedad, a eso que puede mancharnos, a lo podrido, a lo asqueroso, etc. Pero todos estos se refieren aún a un plano físico; sin embargo, la mancha se relacionará también con un peligro para el ser del hombre; esa mancha es también la que lo daña, la que lo ensucia; en última instancia, el pecado. "Entre lo ensuciado, lo consagrado y lo sagrado, las equivalencias y las correspondencias subterráneas son probablemente imborrables; las hierofanías, en tanto que esfera de realidad, son las que engendran el 'régimen ontológico' característico de lo sucio". ${ }^{21}$

Así pues, el símbolo de la mancha, de la suciedad, puede ser considerado como el más antiguo de todos y a su vez uno de los más inagotables, puesto que sus significados se enraízan en la profundidad de lo sagrado y aluden a todo aquello que el hombre experimenta como aterrador, ajeno e incomprensible, que a su vez genera atracción y repulsión.

"Dios santo, qué falta nos hacen los ojos, ver, ver, aunque no fuese más que unas vagas sombras, estar delante de un espejo, mirar una mancha oscura difusa y poder decir, Ahí está mi cara, lo que tenga luz no me pertenece". 22 Saramago introduce así el símbolo de la mancha en su novela, esa mancha que deseamos ver, puesto que nos recuerda nuestro rostro, lo que somos, nuestra miseria, que, por más mísera que sea, es nuestra. Sin embargo, como ya lo he mencionado, la ceguera que padecen los personajes de la novela

20 Saramago, Ensayo sobre la ceguera, 578.

21 Ricoeur, "Para una crítica del símbolo", 12-21.

22 Saramago, Ensayo sobre la ceguera, 54. 
es una mancha, blanca, pero mancha también, que no les permite relacionarse con un mundo que les ha sido negado. Ensucia la visión del mundo y, por ende, a cada uno de quienes la padecen. Por otro lado, es indiscutible la presencia de la suciedad y la inmundicia en la novela de Saramago. Todo se ensucia, se mancha con el paso de los días y con el contagio indiscriminado de la ceguera, que a su vez avanza como una mancha: "saben que en el mundo en el que viven lo que está sucio acabará ensuciándose mucho más".

\section{La culpa}

"Calma, dijo el médico, en una epidemia no hay culpables, todos son víctimas". ${ }^{24}$ La epidemia cumple con la misma función totalizadora que el pecado original, todos somos culpables: "Quién sabe si todo sufrimiento no es, de una u otra manera, el castigo por una falta personal o colectiva, conocida o desconocida?". ${ }^{25}$ Sin necesidad de ser una sociedad creyente o de mucha fe, este cuestionamiento es necesario en cuanto aparece la presencia del sufrimiento. ¿Sufro porque soy culpable? Se evidencia, entonces, ese trasfondo tenebroso del mal como único enigma del que proceden los símbolos de lo que padecemos.

Sobre el fondo simbólico que predisponen la concepción de la mancha, la ruptura del pecado, la impureza y la miseria, se erige la culpabilidad que "representa la forma extrema de interiorización que hemos visto dibujarse al pasar de la impureza al pecado; la impureza todavía era contagio externo, el pecado ya implicaba ruptura de una relación". ${ }^{26}$ En la novela, tal paso de contagio a ruptura es evidente en tanto los personajes empiezan a preguntarse por el porqué de su padecimiento y buscan en el desarrollo de sus propias vidas y su estado ético como humanos una respuesta a este cuestionamiento: "un bribón como este, capaz de robarle a un ciego, se queja de que por mi culpa se quedó ciego, pues eso demuestra que todavía hay justicia en el mundo.". ${ }^{27}$ Otro de los puntos que claramente evidencia la manera en que todos somos culpables, y nos sentimos como tal, es que el autor ha decidido mantener a sus personajes en el anonimato. "Los conocemos tan solo por perífrasis como 'la mujer del médico', 'el oftalmólogo', 'la señorita de las gafas oscuras', 'el niño estrábico'. Ficción pura, real, violenta en el relato de estos ciegos víctimas de una misteriosa y vertiginosa epidemia."28

El simbolismo de la culpa es un simbolismo interior, es el peso que aplasta, es la mordedura del remordimiento y el repensar la falta. Es también una manera de situarse frente a un tribunal que juzga y mide la ofensa y, además, inflige el castigo. "Pero era también el remordimiento, expresión agravada de una conciencia, como antes dijimos, o, si queremos describirlo en términos sugestivos, una conciencia con dientes para morder, quien ponía ante él la imagen desamparada del ciego cerrando la puerta". ${ }^{29}$ Los símbolos del peso y la mordedura manifiestan de manera clara que el plano existencial del hombre ha sido tocado, que es allí donde su situación de culpa se pone al descubierto y se lleva a juicio a sí mismo.

23 Saramago, Ensayo sobre la ceguera, 201.

24 Saramago, Ensayo sobre la ceguera, 38.

25 Ricoeur, El conflicto de las interpretaciones, 284.

26 Ricoeur, El conflicto de las interpretaciones, 386.

27 Saramago, Ensayo sobre la ceguera, 38.

28 Valentina Marulanda, "La novela según Saramago (o lo que va del contar al decir)", Aleph 118 (2001): 25-30.

29 Saramago, Ensayo sobre la ceguera, 17. 
En Ensayo sobre la ceguera, aparece una constante vuelta a la culpabilidad de esa ceguera que se extiende de manera imparable; cada uno de los nuevos ciegos es tan culpable como el anterior y en el fondo de dicha culpa se encuentra un miedo, un temor incalculable a aquello que no conocemos. "Que todos ellos, humanos, se encontrasen ciegos, era una fatalidad de la que no tenían la culpa, son desgracias que llegan, nadie está libre"; ${ }^{30}$ pero, en el fondo, todos se sintieron culpables.

\section{Conclusiones}

La aplicación de una fenomenología de la confesión, específicamente de la confesión del mal, nos lleva a concluir que nuestra tarea para poder comprenderla es repetirla en nosotros mismo como si fuésemos la conciencia confesante. De esta manera, la mancha de la ceguera, el pecado como su causa y el sentimiento de culpabilidad que de ello se deriva pasan a formar parte de lo que como lectores sentimos y comprendemos cuando nos enfrentamos a la sociedad plasmada por Saramago. La simbólica del mal nos ha permitido comprender que somos un solo cuerpo como género humano, unido por los símbolos del pecado y la falta.

La premisa de Ricoeur "el símbolo da qué pensar" es, pues, una invitación a pensar nuestra sociedad desde el símbolo y no por el símbolo. La mancha, el pecado y la culpa son la simbología de nuestra sociedad, son las imágenes sobre las cuales se construyen los paradigmas de la moral, la ética y la convivencia. Pero, para comprenderlos, debemos recurrir necesariamente al lenguaje, a la hermenéutica del símbolo, para desvelar en las profundidades significantes de cada uno de ellos la confesión particular e individual que se hace del mal. La interpretación de dicha confesión nos lleva, entonces, a concluir que la hermenéutica solo puede ser considerada como tal en el momento en que nos permite comprendernos a nosotros mismos en aquello que interpretamos. El que los símbolos de la simbólica del mal de Ricoeur se encuentren presentes en la obra de Saramago no es una coincidencia; dichos símbolos hacen parte del esquema mítico y cosmogónico de todas las sociedades en la historia. La mancha y sus consecuentes ritos de purificación están presentes en sociedades y culturas tan diversas como la egipcia, la babilónica y la judeocristiana, lo cual pone en evidencia que hacen parte de aquel elemento vinculante entre sociedades: el hombre.

Así pues, es pertinente hablar de los símbolos más arcaicos como aquellos que nos facilitan comprender la situación humana en una sociedad, sociedad que en este caso Saramago presenta como en desgracia, lo que facilita identificar el lamento del mal padecido, pero, a su vez, evidenciar la presencia del mal actuado, lo que pone al descubierto al hombre en su situación de vulnerabilidad ante lo sagrado. Actualmente, podemos también percibir nuestra sociedad como una sociedad en desgracia, enfrentada al padecimiento de un mal y la actuación de otros tantos. La realidad de una pandemia, que en este caso no es ceguera, pero que cumple con las características de contagio, sufrimiento y muerte descritas en la novela por el autor, nos invita a interpretar los símbolos con los que nos enfrentamos día a día para nombrar y enunciar en nuestro lenguaje aquello que nos aqueja como humanidad. La sociedad de la novela y el estado del hombre en ceguera e indefensión, de la misma manera que el hombre de hoy, nos deja establecer una comparación que no se escapa a casi ninguno de nosotros: la sociedad en la que hoy vivimos está ciega y es una ceguera causada por el mal que nosotros mismos confesamos.

30 Saramago, Ensayo sobre la ceguera, 17. 


\section{Bibliografía}

Begué, Marie-France. "La simbólica del mal de Paul Ricoeur comentada". Teoliteraria: Revista de Literaturas e Teologias 2, no. 3 (2012): 17-38. https://doi.org/10.19143/2236-9937.2016v2n3p17-38.

Florián, Víctor. Introducción a La llama de una vela, de Gaston Bachelard. Bogotá: Universidad Nacional, 2007. Marulanda, Valentina. "La novela según Saramago". Revista Aleph no. 118 (2001): 25-30.

Ricoeur, Paul. El conflicto de las interpretaciones. Buenos Aires: Aurora, 1976.

Ricoeur, Paul. El conflicto de las interpretaciones. Buenos Aires: Fondo de Cultura Económica, 2008.

Ricoeur, Paul. El mal: Un desafío a la filosofía y a la teología. Buenos Aires: Amorrortu, 2007.

Ricoeur, Paul. Freud: Una interpretación de la cultura. Madrid: Siglo XXI, 1970.

Ricoeur, Paul. La Simbólica del mal interpretada. En El conflicto de las interpretaciones. Buenos Aires: Fondo de Cultura Económica, 2008.

Ricoeur, Paul. "Para una crítica del símbolo". En Freud: Una interpretación de la cultura, 12-21. Madrid: Siglo XXI, 1970.

Saramago, José. Ensayo sobre la ceguera. Lisboa: Caminho, 1995.

Simut, Andrei. "Metaphorical dystopias and the end of the world (s) in Auster's Country of last things and Jose Saramago’s Blindness". Studia Universitatis Babes-Bolyai-Philologia 57, no. 4 (2012): 109-117. 